Sandrine Morel

Giuseppina Milano

Kathi Mujynya Ludunge

Antonio F. Corno

Michele Samaja

Sylvain Fleury

Christophe Bonny

Lukas Kappenberger

Ludwig K. von Segesser

Giuseppe Vassalli

\section{Brief reoxygenation episodes during chronic hypoxia enhance posthypoxic recovery of $L V$ function}

\author{
Role of mitogen-activated protein kinase signaling \\ pathways
}

Received: 14 November 2005

Returned for 1st revision: 25 November 2005 1st Revision received: 10 February 2006 Returned for 2nd revision: 28 November 2005 2nd Revision received: 3 March February 2006 Accepted: 14 March 2006

Published online: 16 May 2006

S. Morel $\cdot$ K.M. Ludunge $\cdot$ S. Fleury

L. Kappenberger · G. Vassalli $(\square)$

Department of Cardiology

University of Lausanne

CHUV, BH10 1011 Lausanne, Switzerland

Tel.: +41-21/31400-76

Fax: +41-21/31400-13

E-Mail: giuseppe.vassalli@chuv.ch

S. Morel · G. Milano · L.K. von Segesser Department of Cardiovascular Surgery

University of Lausanne

Lausanne, Switzerland

A.F. Corno

Department of Cardiac Surgery

Alder Hey Royal Children Hospital

Liverpool, UK

M. Samaja

Department of Medicine

San Paolo Hospital

Milan, Italy

Ch. Bonny

Department of Medical Genetics

University of Lausanne

Lausanne, Switzerland
Abstract Children with congenital cyanotic heart defects have worse outcomes after surgical repair of their heart defects compared with noncyanotic ones. Institution of extracorporeal circulation in these children exposes the cyanotic heart to reoxygenation injury. Mitogenactivated protein kinase (MAPK) signaling cascades are major regulators of cardiomyocyte function in acute hypoxia and reoxygenation. However, their roles in chronic hypoxia are incompletely understood. We determined myocardial activation of the three major MAPKs, c-Jun $\mathrm{NH}_{2}$-terminal kinase (JNK), extracellular signal-regulated kinase-1/2 $(\mathrm{ERK} 1 / 2)$, and $\mathrm{p} 38$-MAPK in adult rats exposed to hypoxia $\left(\mathrm{FIO}_{2}=0.10\right)$ for varying periods of time. Myocardial function was analyzed in isolated perfused hearts. Acute hypoxia stimulated JNK and p38-MAPK activation. Chronic hypoxia (2 weeks) was associated with increased p38MAPK (but not JNK) activation, increased apoptosis, and impaired posthypoxic recovery of LV function. Brief normoxic episodes ( $1 \mathrm{~h} /$ day) during chronic hypoxia abolished p38-MAPK activation, stimulated MEK-ERK1/2 activation modestly, and restored posthypoxic LV function. In vivo p38-MAPK inhibition by SB203580 or SB202190 in chronically hypoxic rats restored posthypoxic LV function. These results indicate that sustained hypoxemia maintains p38-MAPK in a chronically activated state that predisposes to myocardial impairment upon reoxygenation. Brief normoxic episodes during chronic hypoxia prevent p38-MAPK activation and restore posthypoxic recovery of myocardial function.

Key words Mitogen-activated protein kinases - MAPK - p38 hypoxia - reoxygenation

\section{Introduction}

Infants and children with congenital cyanotic defects have their hearts chronically perfused with hypoxemic blood. These children show myocardial damage after surgical correction of their heart defects $[5,6,12,17$, $21,22]$. Institution of cardiopulmonary bypass in these infants exposes the cyanotic heart to sudden reoxygenation. Amongst all conditions that cause myocardial injury, periods of prolonged hypoxemia 
followed by abrupt reoxygenation cause some of the most damaging and irreversible consequences. Experimental evidence suggests that immature hearts are tolerant to ischemia and reperfusion, but susceptible to reoxygenation injury during cardiopulmonary bypass without aortic clamping [11]. Clinical evidence in cyanotic infants and children undergoing surgical repair of congenital heart defects suggests that chronic hypoxemia followed by sudden reoxygenation on cardiopulmonary bypass causes free radical production and impaired postbypass contractility $[5,6,12]$. Ensuing low-output syndrome is the leading cause of prolonged and complicated courses after successful heart surgery in cyanotic infants and children [12, 17, 21, 22].

Stress and mitogen-activated protein kinases (MAPKs) are a family of serine/threonine protein kinases that are activated in response to various extracellular stimuli such as chemical stress, physical stress, radiation, and G-protein-coupled receptor activation. Three major MAPK signaling cascades include stress-activated protein kinases (SAPKs)/cJun N-terminal kinases (JNKs), p38-MAPK (p38 $\alpha$, $\mathrm{p} 38 \beta$, p38 $\gamma$, and $\mathrm{p} 38 \delta$ isoforms), and extracellular signal-regulated kinases (ERKs). Acute myocardial hypoxia and reoxygenation stimulates MAPK activation [19]. However, the roles of MAPKs in chronic hypoxia are still incompletely understood. A recent study showed increased JNK and p38-MAPK activation in cardiac tissues from hypoxic infant rabbits and humans [23]. In the rabbit model, pups were housed in hypoxic chambers but were allowed to return to their mothers and, hence, to breathe room air for a 30-min feeding period daily [23].

Traditionally, hypoxic or hypobaric chambers that were used in previous studies required exposure to room air for a 15-30-min feeding and cleaning period daily $[2,13,23]$. To avoid this confounding factor, we have designed new normobaric hypoxic chambers that allow for daily animal care, drug injection, sacrifice, and organ recovery in the absence of any exposure to room air $[3,20]$. Therefore, the myocardium is chronically perfused with hypoxemic blood. This nonsurgical model mimics physiological (high-altitude) and pathological (congenital heart defects, obstructive lung disease, anemia, microvascular disease) conditions of impaired tissue oxygenation. Unlike previous studies, we used a hypoxic perfusate for initial equilibration of the isolated hypoxic heart to avoid premature reoxygenation. Thus, our model permits to study the response of chronically hypoxemic hearts to the first exposure to high $\mathrm{O}_{2}$ tensions. We used this model to assess myocardial MAPK activation in chronic hypoxia and subsequent reoxygenation. Since previous studies using conventional hypoxic chambers required intermittent exposure to room air, we also studied the effect of repeated brief normoxic episodes on MAPK activation in chronically hypoxic hearts.

\section{Methods}

\section{Experimental groups}

Animal experimentation conformed with the Guide for the Care and Use of Laboratory Animals published by the US National Institutes of Health (NIH Publication No. 8523, revised 1996). Animals were housed in normobaric hypoxic plexiglas chambers that allow for daily maintenance in the absence of any exposure to room air [3]. The oxygen tension inside the hypoxic chamber was continuously monitored by an $\mathrm{O}_{2}$ electrode. We assessed MAPK activation after exposure to a hypoxic environment (fraction of inspired oxygen $\left.\left[\mathrm{FIO}_{2}\right]=0.10\right)$ for varying periods of time (Fig. 1). Sprague-Dawley male rats (5 weeks of age; purchased from IFFACredo, L'Arbresle, France) were subdivided into five groups $(n=6$ / group): (1) Normoxia (N; room air, $\left[\mathrm{FIO}_{2}\right]=0.21$ ); (2) Acute Hypoxia (AH; $1 \mathrm{~h}$ ); (3) Sub-Acute Hypoxia (SAH; $23 \mathrm{~h}$ ); (4) Chronic Hypoxia ( $\mathrm{CH}$; 2 weeks); (5) $\mathrm{CH}$ with intermittent normoxic Aeration (CHA; $\mathrm{FIO}_{2}=0.10$ for $23 \mathrm{~h} /$ day and 0.21 for $1 \mathrm{~h} /$ day during 2 week). To assess the acute effect of a normoxic episode on MAPK activation in $\mathrm{SAH}, \mathrm{CH}$, and $\mathrm{CHA}$, additional rats ( $n=4$ /group) were exposed to room air for $1 \mathrm{~h}$ before the sacrifice.

\section{Isolation of cytosolic and nuclear fractions}

For sacrifice, the rat was moved to a compensation hypoxic chamber attached to the main chamber (same $\mathrm{FIO}_{2}$ ) and injected with a lethal dose of sodium thiopental and $1500 \mathrm{U}$ heparin IP, as described [3]. The heart was explanted and rinsed in ice-cold PBS $(\mathrm{pH}$ 7.4) inside the chamber. Separation of cytosolic and nuclear proteins was performed according to a published protocol [8]. The heart was freeze-clamped between steel tongs pre-cooled with liquid nitrogen. Frozen tissue was homogenized in lysis buffer solution (Hepes $10 \mathrm{mM}, \mathrm{KCl} 10 \mathrm{mM}$, EDTA $0.1 \mathrm{mM}$, EGTA $0.1 \mathrm{mM}$, DTT $1 \mathrm{mM}$, Triton-X100 0.5\%, PMSF $0.5 \mathrm{mM}$, sodiumorthovanadate $1 \mathrm{mM}$, B-glycerophosphate $10 \mathrm{mM}$, NaF $50 \mathrm{mM}$ )

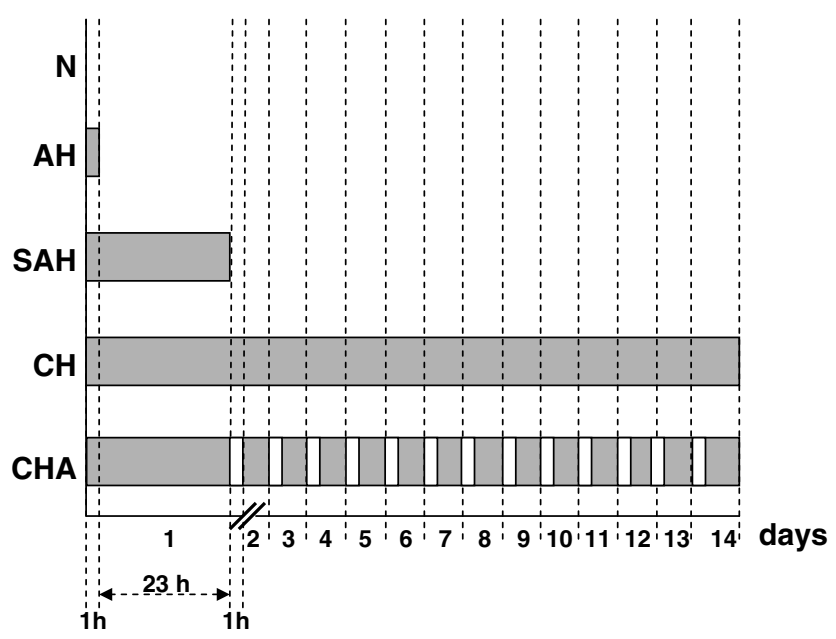

Fig. 1 Scheme of the study protocol. Experimental groups include normoxia $(\mathrm{N})$, acute hypoxia $(\mathrm{AH})$, subacute hypoxia $(\mathrm{SAH})$, chronic hypoxia $(\mathrm{CH})$; and $\mathrm{CH}$ with a 1-h normoxic aeration daily (CHA). Grey horizontal bars indicate hypoxia; white spaces, normoxia (the time scale is not linear) 
containing Protease Inhibitor Cocktail (Roche). After incubation on ice $(10 \mathrm{~min})$, nuclear and cytosolic proteins were separated by centrifugation $\left(1000 \times g, 4^{\circ} \mathrm{C}, 5 \mathrm{~min}\right)$. Supernatant containing cytosolic proteins was transferred to a pre-cooled microcentrifuge tube, frozen in liquid nitrogen, and stored at $-80^{\circ} \mathrm{C}$. The pellet was incubated $\left(4^{\circ} \mathrm{C}, 1 \mathrm{~h}\right)$ in lysis buffer solution (Hepes $20 \mathrm{mM}, \mathrm{NaCl}$ $400 \mathrm{mM}$, EDTA $1 \mathrm{mM}$, EGTA $1 \mathrm{mM}$, DTT $1 \mathrm{mM}$, PMSF $1 \mathrm{mM}$, sodium-orthovanadate $1 \mathrm{mM}$, B-glycerophosphate $10 \mathrm{mM}, \mathrm{NaF}$ $50 \mathrm{mM}$, protease inhibitors). After centrifugation $\left(10,000 \times g, 4^{\circ} \mathrm{C}\right.$, $15 \mathrm{~min}$ ), supernatant containing nuclear proteins was transferred to a cold microcentrifuge tube, frozen in liquid nitrogen, and stored at $-80^{\circ} \mathrm{C}$. Total protein in each fraction was measured by a modified Lowry assay using bovine serum albumin (BSA) as a standard. Purity of cytosolic and nuclear fractions was tested by Western using anti- $\beta$-actin and anti-histone deacetylase-1 (HDAC-1) antibodies, respectively.

\section{Western blot analysis}

SDS-PAGE Western blotting was performed as follows: Proteins $(80 \mu \mathrm{g})$ from cytosolic or nuclear fractions were heated at $95^{\circ} \mathrm{C}$ for $5 \mathrm{~min}$, followed by electrophoresis on a $12 \%$ denaturating gel, and electroblotting onto PVDF membranes. Loading of equal amounts of each MAPK protein for each tissue sample was verified by the intensities of bands obtained with nonphospho-specific antibodies for each MAPK. Membranes were incubated with 5\% nonfat dry milk in TBS-Tween buffer ( $1 \mathrm{~h})$, followed by primary antibody $\left(4^{\circ} \mathrm{C}\right.$, overnight), and HRP-conjugated secondary antibody (RT, $1 \mathrm{~h})$. Phosphorylated MAPK protein levels were determined with phospho-specific antibodies (Cell Signaling Technologies; CST) that recognize phospho-JNK (Thr183/Tyr185), phospho-ERK1/2 (Thr202/Tyr204), or phospho-p38 MAPK (Thr180/Tyr182). Immunoblots were developed by using the LumiGlo reagent/peroxide chemiluminescent system (CST). Band intensities were quantified by using the NIH AutoExtractor-1.51 software. An extract from one normoxic heart was loaded on all blots for quantitative comparisons between blots. Data were normalized to normoxic controls and shown as fold-increases over normoxic levels.

\section{Immunoprecipitation and in vitro kinase assays}

MAPK activities were determined in nuclear and cytosolic fractions by immunoprecipitation, followed by in vitro kinase assays using specific substrates for each MAPK ( $n=6$ /group). For determination of JNK activity, $100 \mu \mathrm{g}$ of tissue extract was incubated (RT, $1 \mathrm{~h}$ ) with $1 \mu \mathrm{g}$ glutathione $S$-transferase (GST)-c-Jun coupled with glutathione beads, as described [1]. After centrifugation $(10,000 \times g, 1 \mathrm{~min})$, the supernatant was removed and the beads were washed twice. Beads were resuspended $\left(30^{\circ} \mathrm{C}, 30 \mathrm{~min}\right)$ in $20 \mu \mathrm{l}$ kinase buffer solution (Hepes $20 \mathrm{mM}, \mathrm{pH} 7.5$, ß-glycerophosphate $20 \mathrm{mM}, \mathrm{MgCl}_{2} 10 \mathrm{mM}$, DTT $1 \mathrm{mM}$,) containing $1 \mu \mathrm{l}\left[\gamma_{-}{ }^{33} \mathrm{P}\right]$ ATP $(3000 \mathrm{ci} / \mathrm{mmol}$; Amersham). Samples were heated at $95^{\circ} \mathrm{C}$ for $5 \mathrm{~min}$, followed by electrophoresis on a $12 \%$ denaturating gel. Phosphorylated c-jun was resolved by autoradiography. For determination of p38-MAPK and ERK $1 / 2$ kinase activities, $200 \mu \mathrm{g}$ tissue extract was incubated $\left(4^{\circ} \mathrm{C}\right.$, overnight) with anti-phospho-p38-MAPK or anti-phospho-ERK1/2, $20 \mu \mathrm{l}$ sepharose-A beads (Amersham), and $50 \mu \mathrm{l}$ BSA. The pellet was washed twice with lysis buffer and twice with kinase buffer solution (Tris $25 \mathrm{mM}, \mathrm{pH} 7.5$, B-glycerophosphate $5 \mathrm{mM}$, DTT $2 \mathrm{mM}$, sodium-orthovanadate $\left.0.1 \mathrm{mM}, \mathrm{MgCl}_{2} 10 \mathrm{mM}\right)$ and incubated $\left(30^{\circ} \mathrm{C}\right.$, $30 \mathrm{~min}$ ) with $50 \mu \mathrm{l}$ kinase buffer solution supplemented with $200 \mu \mathrm{M}$ ATP and $2 \mu \mathrm{g}$ ATF- 2 or ELK-1 fusion proteins (CST) as p38MAPK and ERK1/2-specific substrates, respectively. Reaction was terminated by adding $25 \mu \mathrm{l} 3 \times \mathrm{SDS}$ buffer (Tris-HCl $187.5 \mathrm{mM}, \mathrm{pH}$ 6.8 , SDS $6 \%$, glycerol $30 \%$, DTT $150 \mathrm{mM}$, bromophenol blue $0.03 \%$ ). Samples were heated at $95^{\circ} \mathrm{C}$ for $5 \mathrm{~min}$, followed by electrophoresis on a $12 \%$ denaturating gel, and electroblotting onto nitrocellulose membrane. These were incubated $\left(4^{\circ} \mathrm{C}\right.$, overnight $)$ with anti-phospho-ATF-2 (Thr71) or anti-phospho-ELK-1 (Ser383) (CST), followed by HRP-conjugated secondary antibody (RT, $1 \mathrm{~h}$ ). Immunoblots were developed with LumiGlo reagent/peroxide.

\section{Assessment of oxidative stress and apoptosis}

To assess oxydative stress and myocardial response to hypoxia, we measured plasma malondialdehyde (MDA; an index of lipid peroxidation) and nitrates-nitrites $\left(\mathrm{NO}_{x}\right.$; an index that reflects $\mathrm{NO}$ production), as described previously [20]. Apoptosis was determined on sections of $\mathrm{N}, \mathrm{AH}, \mathrm{SAH}, \mathrm{CH}$, and $\mathrm{CHA}$ hearts $(n=4-6 /$ group) that were immediately processed after the sacrifice. We used terminal deoxynucleotidyl transferase-mediated dUTP-rhodamine nick end labeling (TUNEL; ApopTag Red In Situ Apoptosis detection kit; Intergen). Data are numbers of TUNEL-positive nuclei/microscopic field (mean values \pm SEM) on five random fields (area: $0.037 \mathrm{~mm}^{2}$ each) per heart section (magnification: $400 \times$ ).

\section{Isolated heart perfusion and MAPK inhibitors}

Rat hearts ( $n=7-11 /$ group) were recovered inside the hypoxic chamber, perfused in a retrograde manner with a hypoxic solution, and instrumented as described [3]. After initial equilibration (30 min), hearts were reoxygenated $\left(94 \% \mathrm{O}_{2}\right)$ for $30 \mathrm{~min}$. Rats exposed to $\mathrm{CH}$ received either no treatment, SB202190 or SB203580 ( $1 \mathrm{mg} / \mathrm{kg}$ body weight IP; Calbiochem). Both pyridinylimidazole p38-MAPK inhibitors blocking the kinase catalytic site were given $1 \mathrm{~h}$ before sacrifice. Inhibitory effect on p38-MAPK activity was tested by measuring phosphorylation of Hsp27, a target of p38MAPK, in heart extracts by Western using anti-phospho-Hsp27 [15] Ab (Santa Cruz Biotech.). Normoxic rats that received either p38-MAPK inhibitor, as well as $\mathrm{CH}$ rats that received vehicle alone were used as controls. CHA rats either received no treatment, two doses of PD980592 (2.5 mg/kg body weight/dose IP), a potent and selective inhibitor of MAPK/ERK kinase (MEK1, the upstream activator kinase of ERK1/2) given $6 \mathrm{~h}$ and $30 \mathrm{~min}$ before sacrifice, or vehicle alone (two doses).

\section{Statistical analysis}

Statistical analysis of MAPK activation was performed by use of ANOVA. If significant, the Mann-Whitney test was used as a second step to identify significant differences between individual groups. Analysis of functional recovery in isolated hearts was performed by use of one-way ANOVA with Bonferroni's post-hoc test. Significance was set at $P<0.05$.

\section{Results}

\section{Blood and morphologic data}

Blood and morphologic data are shown in Table 1. The $\mathrm{O}_{2}$ level in the hypoxic chamber never increased by $>1 \%$ during normal maintenance and by $>2 \%$ during sacrifice. Arterial $\mathrm{pO}_{2}$ was $34-38 \mathrm{mmHg}$ in both $\mathrm{CH}$ and $\mathrm{CHA}$ versus $60-70 \mathrm{mmHg}$ in $\mathrm{N}$. Hematocrit, hemoglobin concentration, red blood cell counts, plasma MDA, and $\mathrm{NO}_{x}$ were increased in both $\mathrm{CH}$ and $\mathrm{CHA}$, with a higher increase in $\mathrm{NO}_{x}$ in $\mathrm{CHA}$ versus $\mathrm{CH}(P<0.05)$. $\mathrm{CHA}$ and $\mathrm{CH}$ resulted in re- 
Table 1 Blood and morphological data in normoxic (N), chronically hypoxic $(\mathrm{CH})$, and $\mathrm{CH}$ rats exposed to 1 -h normoxic aeration daily (CHA)

\begin{tabular}{lccc}
\hline & Controls & CH & CHA \\
\hline$N$ & 9 & 11 & 8 \\
Initial body weight, g & $249 \pm 18$ & $247 \pm 7$ & $252 \pm 6$ \\
Hematocrit & $0.44 \pm 0.01$ & $0.69 \pm 0.01^{\mathrm{a}}$ & $0.68 \pm 0.01^{\mathrm{a}}$ \\
Hemoglobin, g/l & $139 \pm 4$ & $220 \pm 5^{\mathrm{a}}$ & $215 \pm 2^{\mathrm{a}}$ \\
Red blood cell count, RBC/ $\mu \mathrm{l} / 1000$ & $7.00 \pm 0.15$ & $10.26 \pm 0.16^{\mathrm{a}}$ & $9.77 \pm 0.19^{\mathrm{a}}$ \\
Final body weight, g & $351 \pm 13$ & $194 \pm 9^{\mathrm{a}}$ & $255 \pm 8^{\mathrm{b}}$ \\
Heart weight, mg & $1312 \pm 43$ & $1127 \pm 35^{\mathrm{a}}$ & $1400 \pm 49^{\mathrm{b}}$ \\
(Heart weight)/(body weight), mg/g & $3.83 \pm 0.04$ & $5.72 \pm 0.19^{\mathrm{a}}$ & $5.25 \pm 0.12^{\mathrm{a}}$ \\
Balloon volume to increase EDP & $75.65 \pm 6.45$ & $81.29 \pm 7.63$ & $56.38 \pm 5.69^{\mathrm{b}}$ \\
$\quad$ from 0 to 10 mmHg, $\mu \mathrm{l}$ & & & \\
$\mathrm{RV} / \mathrm{LV}+$ septum weight ratio & $0.33 \pm 0.02$ & $0.59 \pm 0.03^{\mathrm{a}}$ & $0.59 \pm 0.02^{\mathrm{a}}$ \\
$\mathrm{MDA}, \mathrm{mM}$ & $0.175 \pm 0.018$ & $0.215 \pm 0.015^{\mathrm{a}}$ & $0.213 \pm 0.02^{\mathrm{a}}$ \\
$\mathrm{NO} \mathrm{O}_{x,} \mu \mathrm{MM}$ & $2.58 \pm 0.86$ & $8.82 \pm 1.50^{\mathrm{a}}$ & $12.59 \pm 0.73^{\mathrm{ab}}$ \\
\hline
\end{tabular}

Data are mean values \pm SEM

${ }^{\mathrm{a}} P<0.05$ versus $\mathrm{N}$

${ }^{\mathrm{b}} \mathrm{P}<0.05$ versus $\mathrm{CH}$

$\mathrm{RBC}$, red blood cell counts; $\mathrm{MDA}$, plasma malondialdehyde; $\mathrm{NO}_{x}$, nitrates/nitrites index duced net weight gain and weight loss, respectively. The heart weight/body weight ratio (an index of cardiac hypertrophy) and the RV/LV+septum weight ratio (an index of RV hypertrophy) were increased in both $\mathrm{CH}$ and $\mathrm{CHA}$.

\section{Phosphorylated (activated) MAPK protein levels}

In normoxic hearts, phosphorylated JNK, ERK1/2, and p38-MAPK proteins were present in both cytosolic and nuclear fractions. In combined fractions, phosphoJNK protein levels were increased (fold) by 2.4 in $\mathrm{AH}$ $(P<0.01), 1.8$ in $\mathrm{SAH}(\mathrm{NS}), 1.5$ in $\mathrm{CH}(\mathrm{NS})$, and 1.8 in CHA (NS; Fig. 2A). Phospho-ERK1/2 protein levels in combined fractions were minimally increased in $\mathrm{AH}$ and $\mathrm{SAH}$ (NS), unchanged in $\mathrm{CH}$, and increased by 1.6fold in CHA $(P<0.05)$. Phospho-ERK1/2 protein levels in nuclear fractions were increased by 1.9 -fold in CHA $(P<0.05$ and $<0.01$ versus $\mathrm{N}$ and $\mathrm{CH}$, respectively; Fig. 2C). Phospho-p38-MAPK protein levels were increased (fold) by 3.9 in $\mathrm{AH}(P<0.01)$ and 2.4 in $\mathrm{CH}(P<0.05)$, but marginally decreased in CHA. Phospho-p38-MAPK in nuclear fractions was increased by 4.6 -fold in $\mathrm{CH}(P<0.01$ versus $\mathrm{CHA}$; Fig. 2E). A single normoxic exposure for $1 \mathrm{~h}$ reduced phospho-p38-MAPK in SAH and $\mathrm{CH}$ by $\sim 60 \%$ and $\sim 30 \%$, respectively, while phospho-JNK and phosphoERK1/2 were essentially unaffected (data not shown).

\section{MAPK in vitro kinase activities}

Changes in specific in vitro kinase activities paralleled those in phospho-MAPK protein levels. JNK kinase activity was increased (fold) by 2.8 in $\mathrm{AH}(P<0.01)$, 2.0 in SAH $(P<0.05), 1.3$ in $\mathrm{CH}(\mathrm{NS})$, and 2.2 in CHA $(P<0.05$; Fig. $2 \mathrm{~B})$. ERK $1 / 2$ activity was essentially unchanged in $\mathrm{AH}, \mathrm{SAH}$ and $\mathrm{CH}$, but was increased by 1.6-fold in CHA $(P<0.05$; Fig. 2D). p38-MAPK activity in cytosolic fractions was increased in $\mathrm{AH}$ but not under the other conditions. p38-MAPK activity in nuclear fractions was increased (fold) by 4.9 in $\mathrm{AH}$ $(P<0.01), 1.7$ in $\mathrm{SAH}$, and 2.3 in $\mathrm{CH}(P<0.01)$, whereas it was marginally decreased in CHA (Fig. $2 \mathrm{~F}$ ). Thus, p38-MAPK activity in nuclear fractions was reduced by a factor of 3.3 in $\mathrm{CHA}$ compared with $\mathrm{CH}$ $(P<0.01)$.

\section{Apoptosis}

Numbers of apoptotic cells were determined in both normoxic and hypoxic hearts that were processed immediately after the sacrifice (in the absence of perfusion of the isolated heart). TUNEL-positive cell counts were significantly increased in $\mathrm{AH}, \mathrm{SAH}$ and $\mathrm{CH}$, unlike CHA (Fig. 3).

\section{In vivo p38-MAPK inhibition}

Phosphorylation of Hsp27 was increased 3.6-fold in $\mathrm{CH}$, indicating increased $\mathrm{p} 38$-MAPK activation, but it was suppressed by both SB203580 and SB202190, indicating effective p38-MAPK inhibition (Fig. 4).

\section{Posthypoxic recovery of $L V$ function}

Recovery of LV function upon sudden reoxygenation was analyzed in isolated perfused hearts. Baseline measurements of LV developed pressure $($ LVDP), heart rate $(\mathrm{HR})$, the LVDP $\times$ HR product (Fig. 5), and LV enddiastolic pressure (LVEDP; Fig. 6) were not different between groups. Posthypoxic recovery of $\mathrm{LVDP} \times \mathrm{HR}$ was impaired in $\mathrm{CH}$ but restored in CHA (Fig. 5A, E). Both SB203580 and SB202190 restored LVDP $\times$ HR in CH (Figures 5B,C). Neither p38-MAPK inhibitor affected 

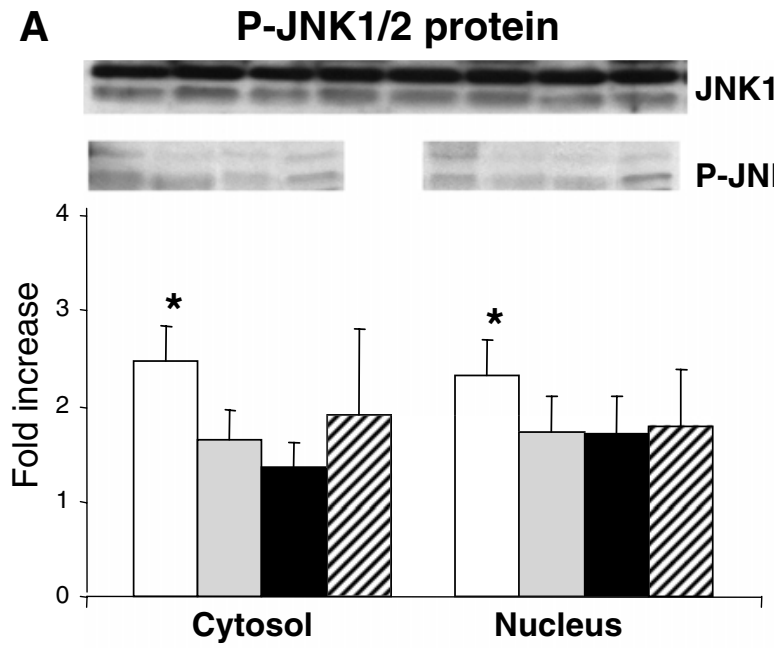

C P-ERK1/2 protein

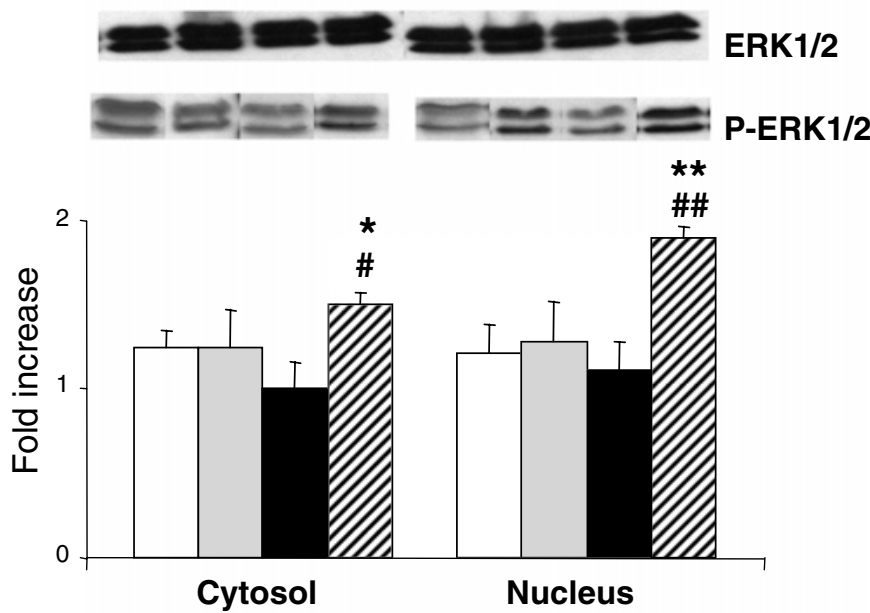

$\mathbf{E}$

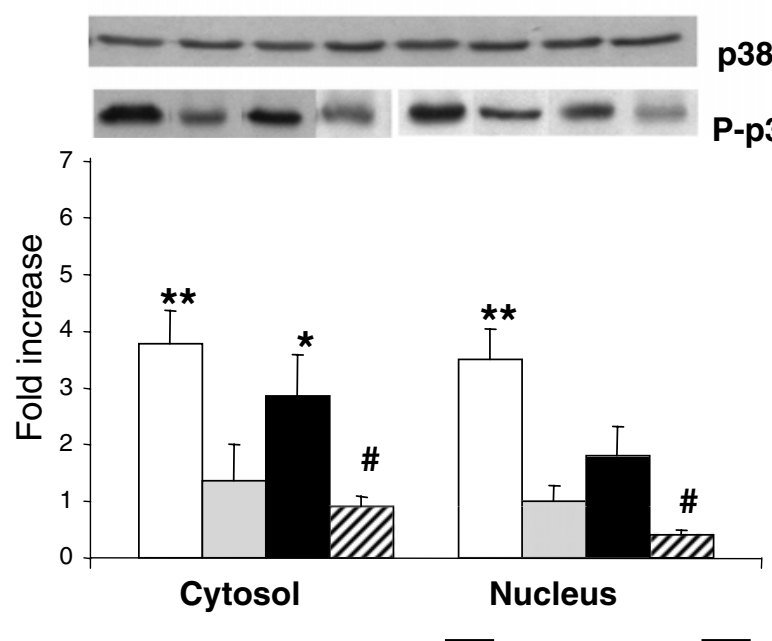

$\mathrm{AH}$

38-MAPK

-p38-MAPK

SAH
B

\section{JNK kinase activity}
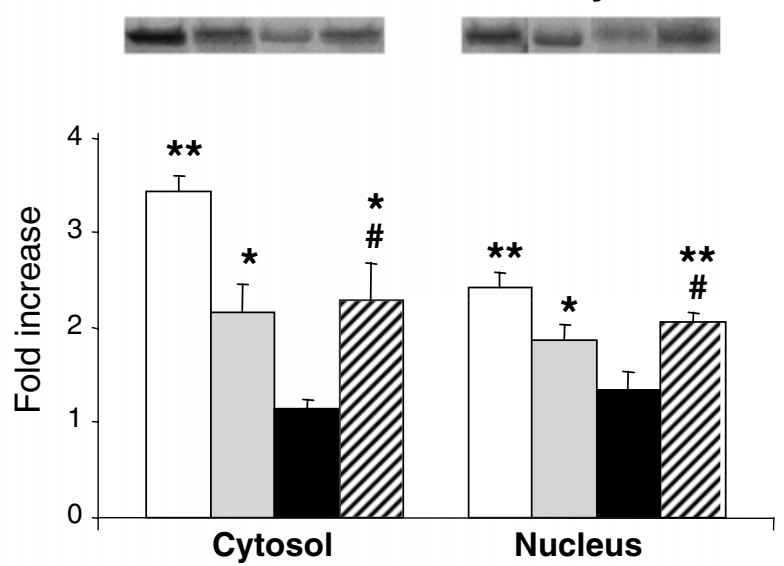

D

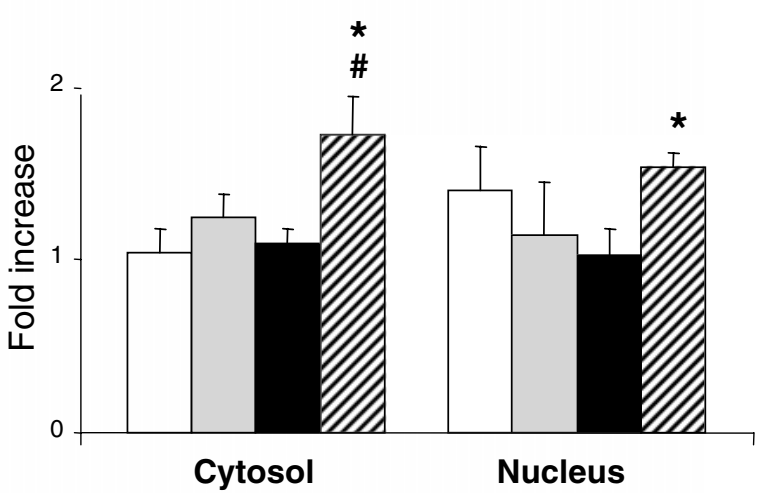

$\mathbf{F}$
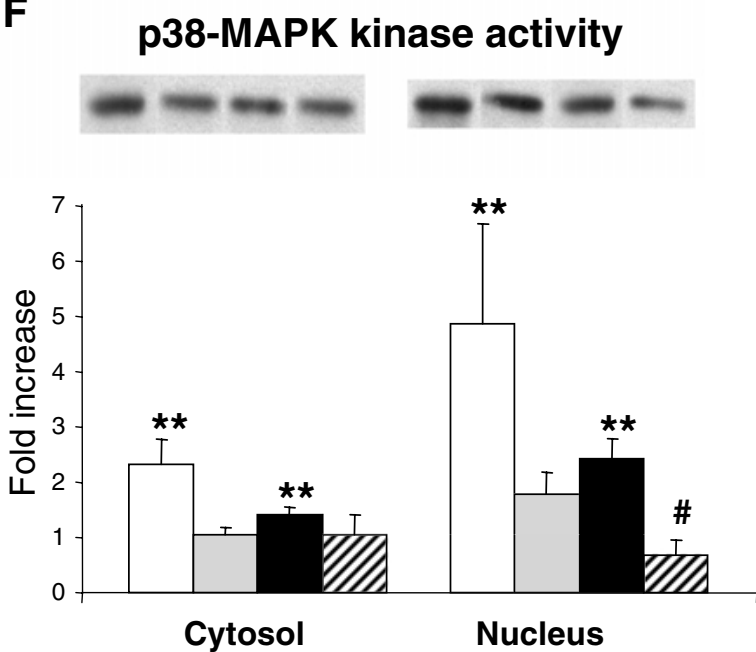

Fig. 2 Left Panels: Phosphorylated MAPK protein levels for JNK (A), ERK1/2 (C), and p38-MAPK (E) in cytosolic and nuclear fractions in rats exposed to $\mathrm{AH}(1 \mathrm{~h}$; white), SAH (grey), CH (black), and CHA (hatched bars). Upper bands show total MAPK proteins, lower bands show corresponding phosphorylated MAPK

proteins. Right panels: Specific in vitro kinase activities for JNK (B), ERK1/2 (D), and p38-MAPK (F). Data are fold-increases (mean \pm SD) over normoxic levels. ${ }^{*} P<0.05$ versus $\mathrm{N}$; ${ }^{*} P<0.01$ versus $\mathrm{N} ; \# P<0.05$ versus $\mathrm{CH}$; \#\#P $<0.01$ versus $\mathrm{CH}$ ( $n=6 /$ group) 


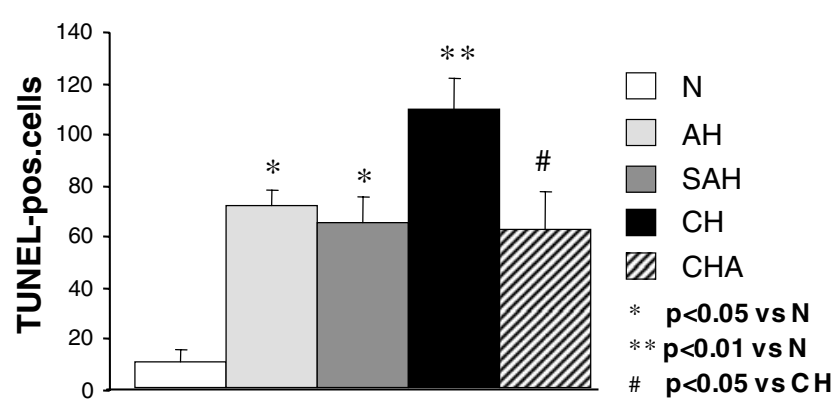

Fig. 3 Apoptosis in N (white), AH (bright grey), SAH (dark grey), CH (black), and CHA (hatched bars) hearts. Data are TUNEL-positive nuclei counts/ microscopic field (mean $\pm \mathrm{SEM}$ ). ${ }^{*} P<0.05$ versus $\mathrm{N}$; ${ }^{* *} P<0.01$ versus $\mathrm{N}$; $\# P<0.05$ versus $\mathrm{CH}$ ( $n=4-6 /$ group)

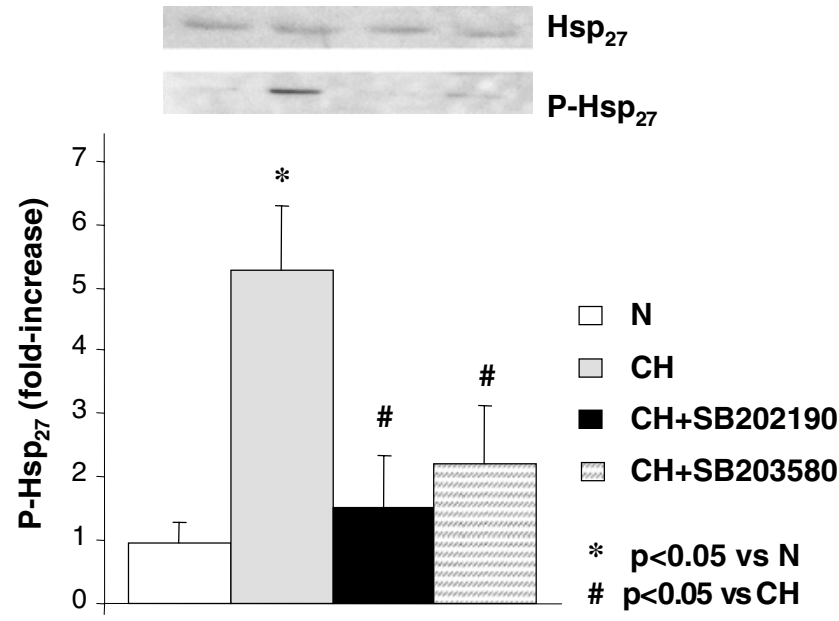

Fig. 4 Phosphorylated Hsp27 protein levels in $\mathrm{N}$ (white), CH (grey), $\mathrm{CH}+\mathrm{SB} 202190$ (black), and CH+SB203580 (hatched bars) hearts. Data are fold-increases (mean \pm SEM) over normoxic levels. ${ }^{*} P<0.05$ versus $N$; $\# P<0.05$ versus $\mathrm{CH}(n=4 /$ group)

LV function per se in normoxic rats. PD98059 did not abolish the improvement in LVDP $\times$ HR in CHA compared with $\mathrm{CH}$ (Fig. 5D, E). Posthypoxic LVEDP was augmented in $\mathrm{CH}$ but normal in $\mathrm{CHA}$ (Fig. 6A, E). Both SB203580 and SB202190 reduced posthypoxic LVEDP in $\mathrm{CH}$, but not in normoxic controls (Fig. 6B, C). PD98059 increased LVEDP in CHA (Fig. 6D, E); however, vehicle alone caused comparable changes (data not shown) consistent with nonspecific effects.

\section{Discussion}

The major findings in the present study are as follows: (1) MAPK signaling cascades are differentially activated in acute and chronic myocardial hypoxia in adult rats; (2) Chronic hypoxia is associated with increased p38-MAPK activation, increased apoptosis, and impaired recovery of LV function upon sudden reoxygenation; (3) Repeated brief normoxic episodes ( $1 \mathrm{~h} /$ day) during chronic hypoxia abolish p38-MAPK activation, stimulate MEK-ERK1/2 activation modestly, and fully restore posthypoxic recovery of LV function; and (4) Pharmacological p38-MAPK blockade similarly restores posthypoxic LV function.

Acute and chronic hypoxia stimulated activation of different MAPK signaling cascades in adult rat myocardium. While acute hypoxia was associated with increased activation of both JNK and p38MAPK, chronic hypoxia enhanced p38-MAPK signaling alone. Thus, sustained hypoxia appears to maintain p38-MAPK in a chronically activated state, which potentially stimulates target nuclear factors and gene expression. This is exemplified by a $\approx 60 \%$ increase in the expression of c-fos, a p38-MAPK target gene, in chronic hypoxia (data not shown). Our results are concordant with recent data showing increased activation of both JNK and p38MAPK in cardiac tissues from chronically hypoxic infant rabbits and humans [23], except that JNK activation was not increased in chronically hypoxic rats in the present study. Methodological factors that could account for differences in JNK activation between the two studies include species, age, and type of hypoxic chambers used. Previous protocols used conventional hypoxic chambers that required a 20-30 min normoxic period daily $[2,13,23]$. In the rabbit model mentioned above [23], infant rabbits were housed in hypoxic chambers but returned to their mothers for a $30 \mathrm{~min}$ feeding period daily, during which they were allowed to breathe room air $[2,23]$. In contrast, we have designed novel hypoxic chambers that avoid any exposure to room air throughout chronic hypoxia (including sacrifice and heart recovery).

Chronic hypoxia was associated with detrimental effects, such as impaired posthypoxic recovery of LV function and increased apoptosis. Previous studies have suggested that the myocardium may adapt to chronic hypoxia and become more tolerant to ischemia-reperfusion injury $[2,7,18,23]$. In a rat model, however, adaptation was confined to the right ventricle [7]. The present study focused on hypoxiareoxygenation, rather than ischemia-reperfusion, injury, which prevents a direct comparison of our results with those obtained in ischemic models. In the clinical setting, hypoxia-reoxygenation injury occurs at institution of cardiopulmonary bypass in cyanotic infants during surgical repair of their heart defects. Experimental studies of hypoxia-reoxygenation injury without aortic clamping showed a higher magnitude of damage compared with ischemia-rep- 

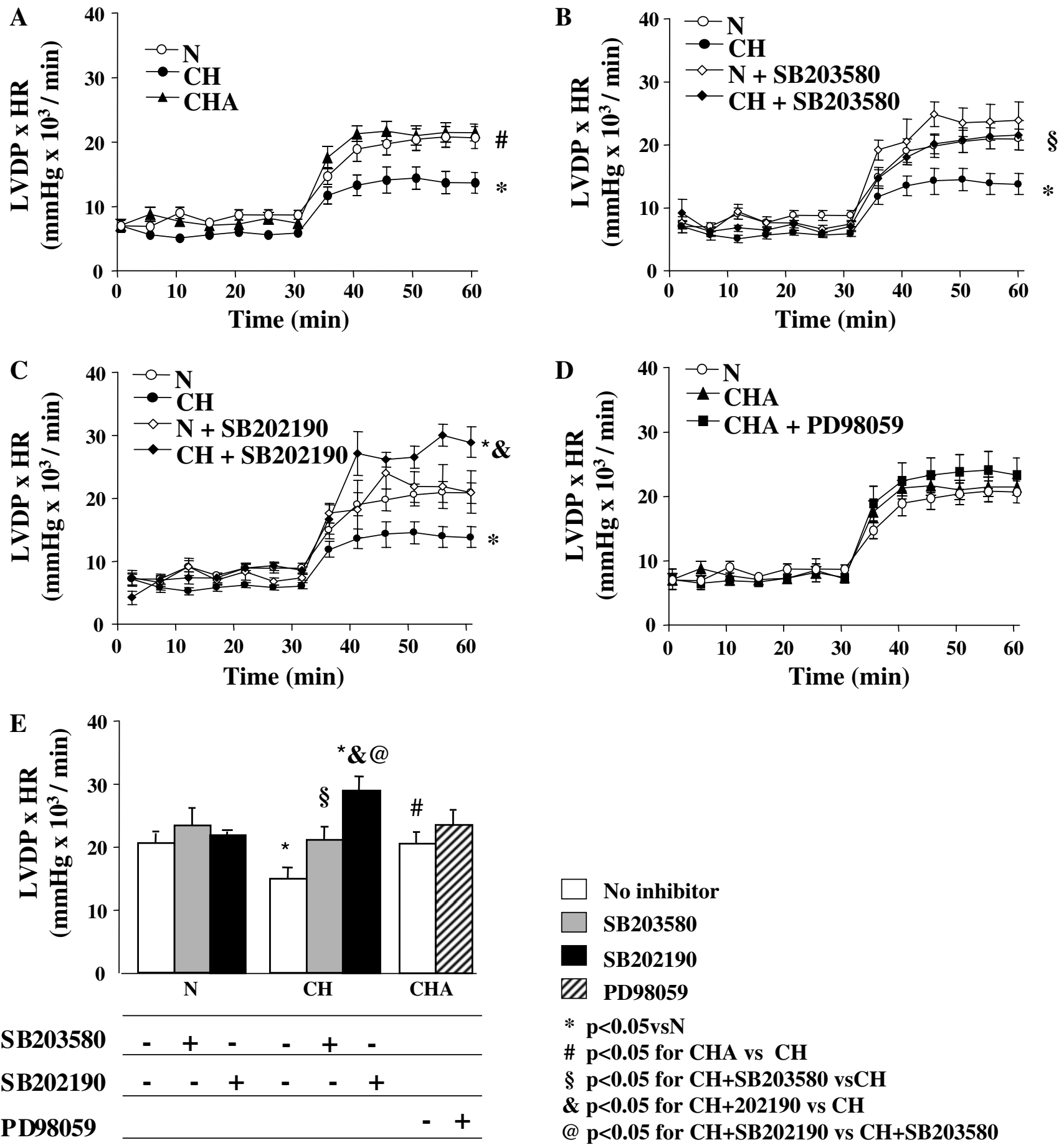

Fig. 5 Posthypoxic recovery of systolic LV function and MAPK inhibitors. (A) LV developed pressure $(\mathrm{LVDP}) \times$ heart rate $(\mathrm{HR})$ product during initial equilibration (starting at time 0 and ending at $30 \mathrm{~min}$ ) and subsequent reoxygenation (starting at $30 \mathrm{~min}$ and ending at $60 \mathrm{~min}$ ). The LVDP $\times$ HR product at the end of reoxygenation was decreased in $\mathrm{CH}$ but normal in CHA. (B, C) Effects of p38MAPK inhibition by SB203580 and SB202190, respectively, in CH and N. Both

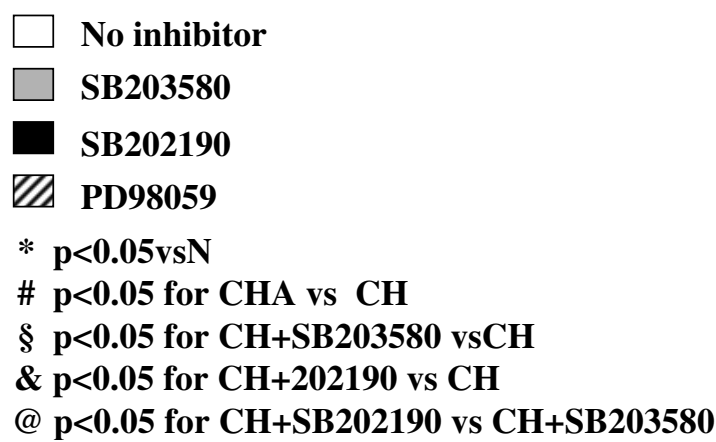

p38-MAPK inhibitors restored posthypoxic LVDP $\times$ HR in $\mathrm{CH}$, but did not induce significant changes in $\mathrm{N}$ hearts. (D) Effect of MEK1-ERK1/2 inhibition in CHA. PD98059 did not affect LVDP $\times$ HR in CHA. (E) Summary graph of the effects of SB203580 (grey bars), SB202190 (black bars), and PD98059 (hatched bars), as compared with no treatment (white bars), on LVDP $\times \mathrm{HR}$ in $\mathrm{N}, \mathrm{CH}$, and CHA. Data are mean values \pm SEM ( $n=7-11 /$ group) 

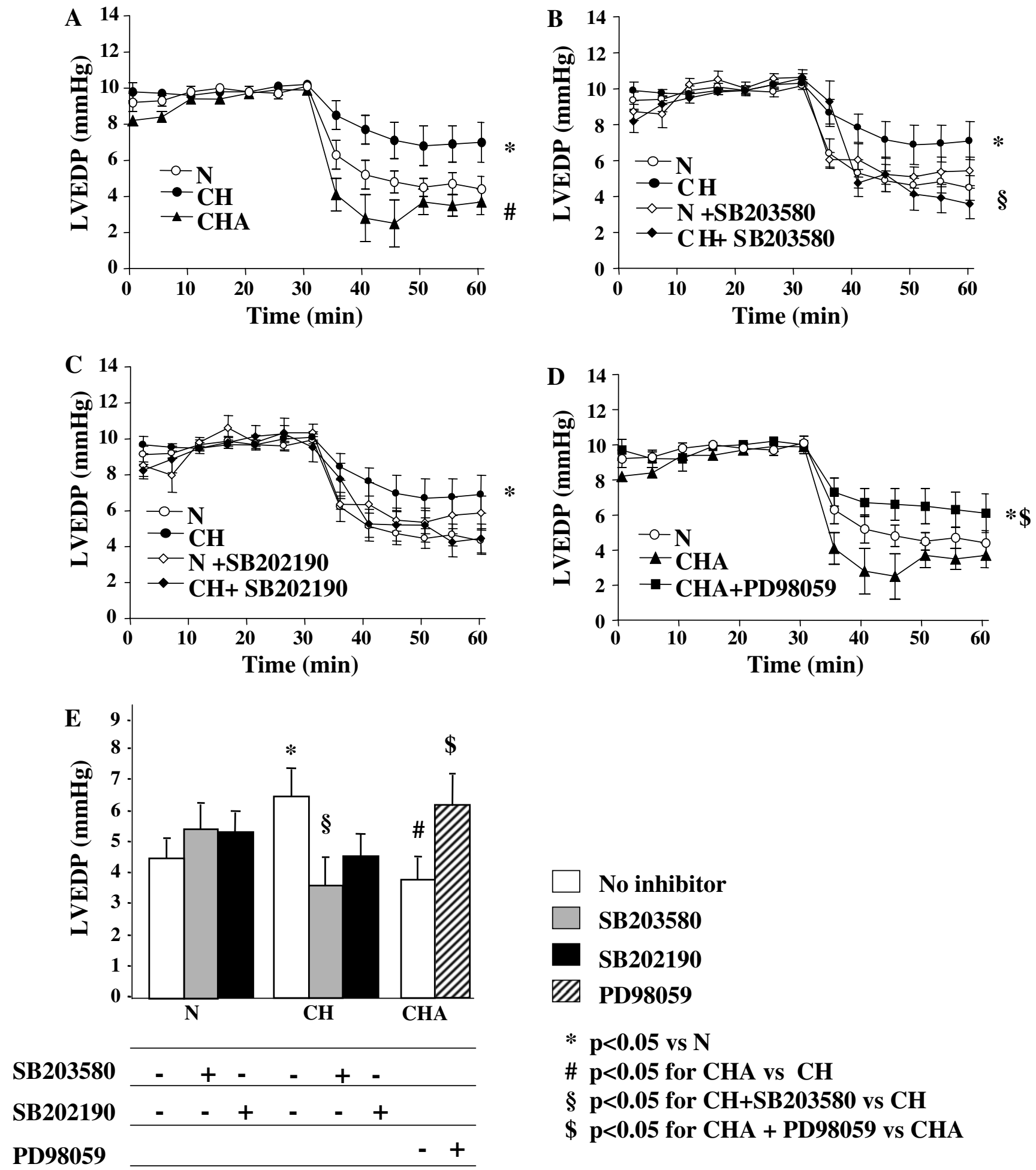

\author{
* $\mathbf{p}<0.05$ vs N \\ \# $\mathbf{p}<\mathbf{0 . 0 5}$ for CHA vs $\mathrm{CH}$ \\ $\S \mathrm{p}<\mathbf{0 . 0 5}$ for $\mathrm{CH}+\mathrm{SB203580}$ vs $\mathrm{CH}$ \\ $\$ \mathbf{p}<0.05$ for CHA + PD98059 vs CHA
}

Fig. 6 Posthypoxic recovery of diastolic LV function and MAPK inhibitors. (A) LV end-diastolic pressure (LVEDP) during initial equilibration (starting at time 0 and ending at $30 \mathrm{~min}$ ) and subsequent reoxygenation (starting at $30 \mathrm{~min}$ and ending at $60 \mathrm{~min}$ ). LVEDP at the end of reoxygenation was increased in $\mathrm{CH}$ but normal in CHA. (B, C) Effects of p38-MAPK inhibition by SB203580 and SB202190, respectively, in CH and N. Both p38-MAPK inhibitors normalized

LVEDP in $\mathrm{CH}$ but did not reduce it in $\mathrm{N}$ hearts. (D) Effect of MEK1-ERK1/2 inhibition in CHA. PD98059 increased LVEDP in CHA (similar changes were observed with vehicle alone; data not shown). (E) Summary graph of the effects of SB203580 (grey bars), SB202190 (black bars), and PD98059 (hatched bars), as compared with no treatment (white bars), on LVEDP in N, CH, and CHA ( $n=7-11$ /group). Data are mean values \pm SEM 
erfusion injury [11]. Our results are in good agreement with a few studies in large animal models in which chronic hypoxia was induced by using surgical techniques [9, 16, 25]. In addition, they are consistent with clinical evidence suggesting that cyanotic infants and children have a higher incidence of prolonged and complicated courses after successful heart surgery compared with noncyanotic ones $[12,17,21,22]$. Again, it is conceivable that some protective effects attributed to chronic hypoxia in models that utilized conventional hypoxic chambers were actually due to intermittent normoxic episodes during daily opening of the cages.

In the present study, exposure of chronically hypoxic rats to room air for a $1 \mathrm{~h}$ period daily abolished p38-MAPK, while enhancing MEK1-ERK1/2 activation modestly. In comparison, a $1 \mathrm{~h}$ exposure to room air following 2 weeks of hypoxia reduced phosphorylated p38-MAPK protein levels by just $\approx 30 \%$. Intermittent reoxygenation for $1 \mathrm{~h} /$ day was paralleled by decreased apoptosis and restored posthypoxic recovery of LV function in chronically hypoxic hearts. Although cardioprotection mediated by intermittent hypoxia (4-6 h/day) was reported recently [28], it is worth noting that our results refer to intermittent reoxygenation $(1 \mathrm{~h} /$ day) during chronic hypoxia, rather than intermittent hypoxia. The mechanism underlying the protective effect is incompletely understood. Bursts of reactive oxygen species generated during normoxic exposure after prolonged hypoxia add to oxidative stress, as evidenced by increased $\mathrm{NO}_{x}$ in the present study. It has been shown that oxidative stress induced by preconditioning contributes to the second window of protection by endogenous antioxidant enzymes in myocytes [27].

The role of $\mathrm{p} 38$-MAPK in hypoxia-reoxygenation injury is still controversial. p38-MAPK has been implicated in ischemic preconditioning in a pig model [24]. A number of factors, such as species, age, preconditioning, hypoxia-reoxygenation or ischemia-reperfusion injury, and timing of drug administration have been shown to influence the outcome of p38-MAPK inhibition [24]. In the present study, two different p38-MAPK inhibitors, SB203580 and SB202190, abolished p38-MAPK activation and restored posthypoxic recovery of $\mathrm{LV}$ function in chronically hypoxic rats, in the absence of nonspecific effects in normoxic hearts. These findings support a central role for p38-MAPK as a negative regulator of myocardial function in chronic hypoxia. They are consistent with recent data showing that $\mathrm{p} 38$-MAPK mediates a negative inotropic effect in cardiomyocytes [14].
At least four members of the p38-MAPK family have been identified, and its variable effects may be accounted for by the relative expression of a particular isoform. The isoforms $\alpha$ and $\beta$ are both expressed in the heart and may have opposing effects. Ischemia activates the p38 $\alpha$ but not $\mathrm{p} 38 \beta$ isoform in myocytes, a potentially detrimental pattern. The two p38-MAPK inhibitors used in the present study inhibit both $\mathrm{p} 38 \alpha$ $(\mathrm{SAPK} \alpha)$ and $\mathrm{p} 38 \beta\left(\mathrm{SAPK} \beta_{2}\right)$ [4]. The distinct roles of p $38 \alpha$ and $\mathrm{p} 38 \beta$ in myocardial impairment in chronic hypoxia remain to be determined.

In the present study, we mainly focused on p38MAPK activation as the most pronounced effect of chronic hypoxia on the three major MAPK families. Pharmacological p38-MAPK inhibition was sufficient to fully reverse the detrimental effect of chronic hypoxia on posthypoxic LV function. Thus, p38-MAPK inhibition induced by brief normoxic episodes during chronic hypoxia would be sufficient to explain the protective effect observed. Contributory roles for ERK1/2 [15] and JNK activation to this effect are possible, but have not been extensively characterized in the present study. Intermittent reoxygenation activated the MEK1-ERK1/2 signaling pathway only modestly, and the protective effect was not abrogated by PD98059, a specific MEK1 inhibitor. Moreover, intermittent reoxygenation induced in vitro JNK activity only modestly in nuclear fractions, and this was not accompanied by a parallel increase in phosphorylated JNK protein levels. Further investigations are needed to more precisely characterize the biological relevance of the modest changes in ERK1/2 and JNK activation induced by intermittent reoxygenation in the present study.

Experimental evidence for hypoxic adaptation does not appear to translate into any clinically relevant cardiac protection in children undergoing surgical repair of a cyanotic heart defect. Our data suggest that preoperative intermittent reoxygenation and pharmacological p38-MAPK inhibition might be beneficial. Parenthetically, it has been shown that breathing hyperoxic gas $\left(\left[\mathrm{FIO}_{2}\right]=0.80\right)$ for $1 \mathrm{~h}$ induces both immediate and delayed cardioprotection in rats [26]. Regarding pharmacological approaches, a specific p38-MAPK inhibitor is being tested in initial clinical trials in rheumatoid arthritis [10]. Further studies are needed to evaluate the usefulness of these approaches in preclinical models of chronic hypoxia.

Acknowledgments The study was supported by the Teo Rossi di Montelera Foundation, the Swiss Cardiology Foundation, the Fondation Vaudoise de Cardiologie, the Fondation Lausannoise de Transplantation, and the "Heart Remodeling in Health and Disease" program sponsored by the Swiss University Conference. 


\section{References}

1. Abdelli S, Ansite J, Roduit R, Borsello T, Matsumoto I, Sawada T, AllamanPillet N, Henry H, Beckmann JS, Hering BJ, Bonny C (2004) Intracellular stress signaling pathways activated during human islet preparation and following acute cytokine exposure. Diabetes 53:2815-2823

2. Baker JE, Curry BD, Olinger GN, Gross GJ (1997) Increased tolerance of the chronically hypoxic immature heart to ischemia. Contribution of the KATP Channel. Circulation 95:1278-1285

3. Corno A, Milano G, Samaja M, Tozzi P, von Segesser LK (2002) Chronic hypoxia. A model for cyanotic heart defects. J Thorac Cardiovasc Surg 124:105-112

4. Davies SP, Reddy H, Caivano M, Cohen P (2000) Specificity and mechanism of action of some commonly used protein kinase inhibitors. Biochem J 251:95105

5. Del Nido PJ, Mickle DA, Wilson GJ, Benson LN, Coles JG, Trusler GA, Williams WG (1987) Evidence of myocardial free radical injury during elective repair of tetralogy of Fallot. Circulation 76(5 Pt 2):V174-V179

6. Dhaliwal H, Kirschenbaum LA, Ranfhawa AK, Singal PK (1990) Correlation between antioxidant changes during hypoxia and recovery on reoxygenation. Am J Physiol 261:H632-H638

7. Forkel J, Chen X, Wandinger S, Keser F, Duschin A, Schwanke U, Frede S, Massoudy P, Schulz R, Jakob H, Heusch G (2004) Responses of chronically hypoxic rat hearts to ischemia: $\mathrm{K}_{\mathrm{ATP}}$ channel blockade does not abolish increased RV tolerance to ischemia. Am J Physiol Heart Circ Physiol 286:H545H551

8. Fryer R, Pratt P, Hsu A, Gross G (2001) Differential activation of extracellular signal regulated kinase isoforms in preconditioning and opioid-induced cardioprotection. J Pharmacol Exp Ther 296:642-649

9. Fujiwara T, Kurtts T, Anderson W, Heinle J, Mayer JE Jr (1998) Myocardial protection in cyanotic neonatal lambs. J Thorac Cardiovasc Surg 96:700-710

10. Haddad JJ (2001) VX-745. Vertex Pharmaceuticals. Curr Opin Investig Drugs 2:1070-1076
11. Ihnken K, Morita K, Buckberg GD, Sherman MP, Young HH (1995) Studies of hypoxemic/reoxygenation injury: without aortic clamping. III. Comparison of the magnitude of damage by hypoxemia/reoxygenation versus ischemia/reperfusion. J Thorac Cardiovasc Surg 110(4 Pt 2):1182-1189

12. Imura $H$, Caputo $M$, Parry $A$, Pawade A, Angelini GD, Suleiman MS (2001) Age-dependent and hypoxia-related differences in myocardial protection during pediatric open heart surgery. Circulation 103:1551-1556

13. Jung F, Weiland U, Johns RA, Ihling C, Dimmeler S (2001) Chronic hypoxia induces apoptosis in cardiac myocytes: a possible role for Bcl-2-like proteins. Biochem Biophys Res Comm 286:419425

14. Liao P, Wang SQ, Wang S, Zheng $M$, Zheng $M$, Zhang SJ, Cheng $\mathrm{H}$, Wang $\mathrm{Y}$, Xiao RP (2002) p38 mitogen-activated protein kinase mediates a negative inotropic effect in cardiac myocytes. Circ Res 90:190-196

15. Lips DJ, Bueno OF, Wilkins BJ, Purcell $\mathrm{NH}$, Kaiser RA, Lorenz JN, Voisin L, Saba-El-Leil MK, Meloche S, Pouyssegur J, Pages G, De Windt LJ, Doevendans PA, Molkentin JD (2004) MEK1ERK2 signaling pathway protects myocardium from ischemic injury in vivo. Circulation 109:1938-1941

16. Lupinetti FM, Wareing TH, Huddleston CB, Collins JC, Boucek RJ Jr, Bender HW Jr, Hammon JW Jr (1985) Pathophysiology of chronic cyanosis in a canine model. Functional and metabolic response to global ischemia. J Thorac Cardiovasc Surg 90:291-296

17. McElhinney DB, Wernovsky G (2001) Outcomes of neonates with congenital heart disease. Curr Opin Pediatr 13:104-110

18. Meerson FZ, Gomzakov OA, Shimkovich MV (1973) Adaptation to high altitude hypoxia as a factor preventing development of myocardial ischemic necrosis. Am J Cardiol 31:30-34

19. Michel MC, Li Y, Heusch G (2001) Mitogen-activated protein kinases in the heart. Naunyn-Schmiedeberg's Arch Pharmacol 363:245-266

20. Milano G, Bianciardi P, Corno AF, Raddatz E, Morel S, von Segesser LK, Samaja M (2004) Myocardial impairment in chronic hypoxia is abolished by short aeration episodes: Involvement of $\mathrm{K}^{+}{ }_{\text {ATP }}$ channels. Exp Biol Med 229:1196-1205
21. Modi P, Imura H, Caputo M, Pawade A, Parry A, Angelini GD, Suleiman MS (2002) Cardiopulmonary bypass-induced myocardial reoxygenation injury in pediatric patients with cyanosis. J Thorac Cardiovasc Surg 124:1035-1036

22. Najm HK, Wallen WJ, Belanger MP, Williams WG, Coles JG, Van Arsdell GS, Black MD, Boutin C, Wittnich C (2000) Does the degree of cyanosis affect myocardial adenosine triphosphate levels and function in children undergoing surgical procedures for congenital heart disease? J Thorac Cardiovasc Surg 119:515-524

23. Rafiee P, Shi Y, Kong X, Pritchard KA Jr, Tweddell JS, Litwin SB, Mussatto K, Jaquiss RD, Su J, Baker JE (2002) Activation of protein kinases in chronically hypoxic infant human and rabbit hearts. Role in cardioprotection. Circulation 106:239-245

24. Schulz R, Belosjorow S, Gres P, Jansen J, Michel MC, Heusch G (2002) p38 MAPK is a mediator of ischemic preconditioning in pigs. Cardiovasc Res 55:690-700

25. Silverman NA, Kohler J, Levitsky S, Pavel DG, Fang RN, Feinberg H (1984) Chronic hypoxemia depresses global ventricular function and predisposes the depletion of high-energy phosphates during cardioplegic arrest: implications for surgical repair of cyanotic congenital heart defects. Ann Thorac Surg 37:304-308

26. Tähepold P, Ruusalepp A, Li G, Vaage J, Starkopf J, Valen G (2002) Cardioprotection by breathing hyperoxic gas - relation to oxygen concentration and exposure time in rats and mice. Eur J Card Thorac Surg 21:987-994

27. Zhou X, Zhai X, Ashraf M (1996) Direct evidence that initial oxidative stress triggered by preconditioning contributes to second window of protection by endogenous antioxidant enzyme in myocytes. Circulation 93:1177-1184

28. Zhu HF, Dong JW, Zhu WZ, Ding HL, Zhou Z (2003) ATP-dependent potassium channels involved in the cardiac protection induced by intermittent hypoxia against ischemia/reperfusion injury. Life Sci 73:1275-1287 